\title{
Improving survival in immunocompromised patients with hypoxemic acute respiratory failure
}

\author{
Guillaume Dumas $^{1,2}$, Virginie Lemiale ${ }^{1}$, Alexandre Demoule ${ }^{3}$, Elie Azoulay ${ }^{1,2}$ \\ ${ }^{1}$ Medical Intensive Care Unit, Saint-Louis Teaching Hospital, Paris, France; ${ }^{2}$ ECSTRA Team, Biostatistics and Clinical Epidemiology, UMR 1153 \\ (Center of Epidemiology and Biostatistic Sorbonne Paris Cité, CRESS), INSERM, Paris Diderot University, Paris, France; ${ }^{3}$ Groupe Hospitalier \\ Pitié-Salpêtrière Charles Foix, Service de Pneumologie, Médecine Intensive et Réanimation (Département R3S), AP-HP, INSERM, UMRS1158 \\ Neurophysiologie Respiratoire Expérimentale et Clinique, Sorbonne Université, Paris, France \\ Correspondence to: Professor Elie Azoulay. Medical Intensive Care Unit, Hôpital Saint-Louis, ECSTRRA Team, Biostatistics and Clinical \\ Epidemiology, UMR 1153 (Center of Epidemiology and Biostatistic Sorbonne Paris Cité, CRESS), INSERM, Paris Diderot University, Medical \\ Intensive Care Unit, Hôpital Saint-Louis, 1 Avenue Claude Vellefaux, 75010 Paris, France. Email: elie.azoulay@aphp.fr. \\ Provenance: This is an invited article commissioned by the Section Editor Dr. Guo-Wei Tu (Department of Critical Care Medicine, Zhongshan \\ Hospital, Fudan University, Shanghai, China). \\ Comment on: Coudroy R, Pham T, Boissier F, et al. Is immunosuppression status a risk factor for noninvasive ventilation failure in patients with acute \\ hypoxemic respiratory failure? A post hoc matched analysis. Ann Intensive Care 2019;9:90.
}

Submitted Oct 29, 2019. Accepted for publication Nov 05, 2019.

doi: $10.21037 /$ atm.2019.11.45

View this article at: http://dx.doi.org/10.21037/atm.2019.11.45

Over the last two decades, the number of patients living with immune deficiency has steadily increased (1). Even though a greater life expectancy could be achieved (2), immunocompromised patients still experience lifethreatening complications warranting admission to the intensive care unit (ICU), chiefly for hypoxemic acute respiratory failure (ARF). Case fatality is high in ARF patients, especially when endotracheal intubation (ETI) is needed (3). Hence, oxygenation and ventilation strategies to avoid invasive mechanical ventilation have been widely evaluated in this setting. The single center trial from Hilbert et al. (4) which reported a significant reduction in intubation and mortality rates associated with noninvasive ventilation (NIV) has been challenged by larger and multicenter data $(5,6)$.

In a paper published recently in Annals of Intensive Care, Coudroy et al. (7) investigated whether immunosuppression was a determinant of NIV failure. They used pooled data from a prospective randomized trial of oxygenation strategies in unselected patients combined to those from a single center retrospective study (8) and applied a propensity-score matching approach leaving only 108 of the 208 patients for the final analysis.

Using this set of pooled data, they found that immunosuppression status was not associated with NIV failure but only with mortality rate. This finding, if confirmed in studies adequately powered for this endpoint, is an important one as it suggests that discrepancies across studies may either be ascribable to different patient's severity or to differences in criteria for intubation. Along this line, authors identified the degree of hypoxemia $\left(\mathrm{PaO}_{2} /\right.$ $\mathrm{FiO}_{2}$ after 1 hour of NIV trial) as associated with NIV failure. The finding that expired tidal volume (ETV) was associated with NIV failure on the entire cohort but not on the matched sample also suggests that this sound and valid hypothesis should be validated in larger prospective studies. These results taken together with previously published data $(5,9)$ raise awareness that NIV should not be used anymore in patients with criteria of ARDS, especially in patients remaining with a high respiratory drive despite optimal pressure support. ETV in these high risk patients with hypoxemic ARF could be used to risk-stratify patients unlikely to benefit from NIV, if not those in whom NIV is an actual harm because of the high respiratory drive exposing them to self-inflected lung injury $(9,10)$. All of these factors have been already reported and summarized in a easy to use mnemonic, namely, the HACOR score for Heart rate, Acidosis, Consciousness, Oxygenation and 


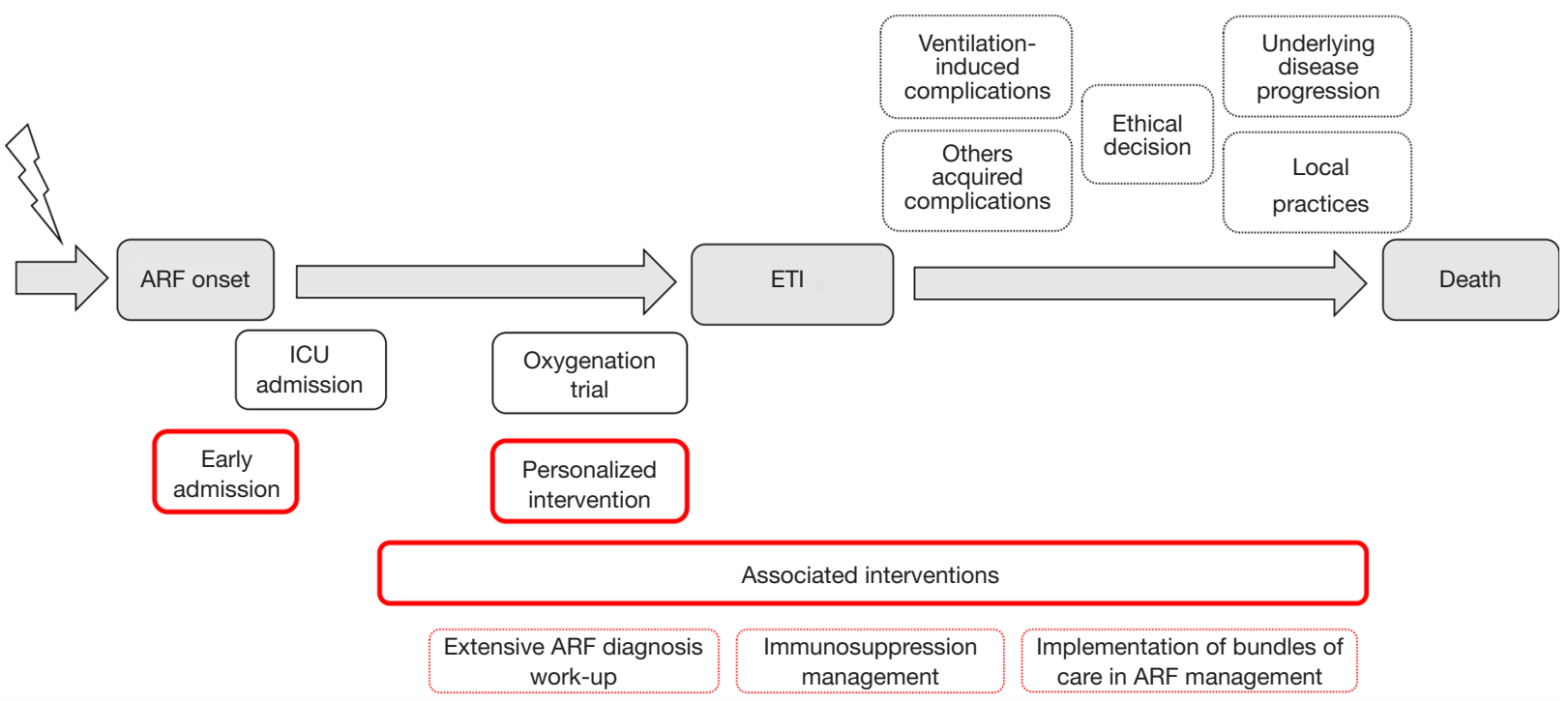

Figure 1 Schematic representation of causal pathway from acute respiratory failure onset to death with traditional and new proposed concepts in its management. Grey boxes show representation of causal pathway with classical intervention (Black boxes). Red boxes show potential targets for prognosis improvement. ARF, acute respiratory failure; ETI, endotracheal intubation.

Respiratory rate, to identify patients at high risk for NIV failure (11). Noteworthy, immunocompromised patients of the present cohort have a significant higher severity score at ICU admission as well as more severe clinical respiratory presentation than non-immunocompromised ones. These features are suggestive of delayed admission to the ICU. Studies to compare immunocompromised and nonimmunocompromised patients should address the specific issue of timing of ICU admission as it has been associated with mortality (12).

This study also raises the question of the causal pathway between initial oxygenation therapy, need for intubation and death (Figure 1). Over the past two decades, studies have primarily focused on the initial oxygenation strategy, with various devices (CPAP, NIV with mask or helmet, high-flow nasal canula, standard oxygen therapy) in order to avoid ETI (4,5,13-17). However, based on large number of patients, data are now convincing to ascertain that strategies to improve survival should not target oxygenation and ventilation strategies (5,6,17-19). Most importantly, as mortality in intubated patients remains high (Table 1), we suggest the use of another agenda to further reduce case fatality in hypoxemic patients with ARF. For instance, three major targets should better be evaluated: (I) optimal timing of ICU admission; (II) clinician's ability to personalize the appropriate oxygenation strategy for a given patient; and (III) selecting the most appropriate diagnostic strategy to avoid leaving the patient with an undetermined ARF etiology, a situation at risk for increased mortality $(6,20)$. In addition, preventing ICU acquired events from both invasive mechanical ventilation and underlying impairment of immunological functions will also be challenging $(3,12,21)$. Future research agenda will have to address these unanswered questions. Large prospective cohorts and clinical trials with adaptive design have the potential to identify which patient could benefit from a given diagnostic or therapeutic strategy, as well as a better stratification of specific risks through machine learning advances $(22,23)$.

That immunocompromised and non-immunocompromised patients can be managed the same way with regard to oxygenation and ventilation strategy is very likely. However, it is time now to understand that survival benefits will not come from this research. Studies to improve global medical management based on updated strategies and newly developed diagnostic tools are warranted.

\section{Acknowledgments}

None.

\section{Footnote}

Conflicts of Interest: The authors have no conflicts of interest to declare. 
Table 1 Randomized controlled trial of oxygenation/ventilation strategies specifically dedicated to immunocompromised patients with hypoxemic acute respiratory failure

\begin{tabular}{|c|c|c|c|c|c|}
\hline Authors, review, year of publication & $\mathrm{N}$ & Intervention/control & $\begin{array}{l}\text { No. of } \\
\text { centers }\end{array}$ & $\begin{array}{c}\text { IMV rate, } \\
\%\end{array}$ & $\begin{array}{c}\text { In-ICU Mortality rate in IMV } \\
\text { patients, } \%\end{array}$ \\
\hline Antonelli et al., JAMA, 2000 & 40 & $\mathrm{NIV} / \mathrm{O}_{2}$ & 1 & 45 & 78 \\
\hline Squadrone et al., Intensive care Med, 2010* & 40 & $\mathrm{CPAP} / \mathrm{O}_{2}$ & 1 & 40 & 100 \\
\hline Wermke et al., Bone Marrow Transpl, 2012* & 90 & $\mathrm{NIV} / \mathrm{O}_{2}$ & 1 & 20 & 100 \\
\hline Lemiale et al., JAMA, 2015 & 374 & $\mathrm{NIV} / \mathrm{O}_{2}{ }^{* *}$ & 28 & 42 & 52 \\
\hline Azoulay et al., JAMA, 2018 & 776 & $\mathrm{HFNC} / \mathrm{O}_{2}$ & 31 & 41 & 56 \\
\hline Total & 1,472 & - & - & 41.2 & 74.3 \\
\hline
\end{tabular}

Only studies published in English from Jan 01, 2000, to March 31, 2019, were taken into account. *, patients included in ward; **, 127 patients received HFNC therapy. NIV, non-invasive ventilation; $\mathrm{O}_{2}$, standard oxygen therapy; HFNC, high-flow nasal cannula oxygen therapy; IMV, invasive mechanical ventilation.

Ethical Statement: The authors are accountable for all aspects of the work in ensuring that questions related to the accuracy or integrity of any part of the work are appropriately investigated and resolved.

\section{References}

1. Harpaz R, Dahl RM, Dooling KL. Prevalence of Immunosuppression Among US Adults, 2013. JAMA 2016;316:2547-8.

2. Jemal A, Ward EM, Johnson CJ, et al. Annual Report to the Nation on the Status of Cancer, 1975-2014, Featuring Survival. J Natl Cancer Inst 2017. doi:10.1093/jnci/djx030.

3. Azoulay E, Mokart D, Pène F, et al. Outcomes of critically ill patients with hematologic malignancies: prospective multicenter data from France and Belgium--a groupe de recherche respiratoire en réanimation onco-hématologique study. J Clin Oncol 2013;31:2810-8.

4. Hilbert G, Gruson D, Vargas F, et al. Noninvasive ventilation in immunosuppressed patients with pulmonary infiltrates, fever, and acute respiratory failure. $\mathrm{N} \mathrm{Engl} \mathrm{J}$ Med 2001;344:481-7.

5. Lemiale V, Mokart D, Resche-Rigon M, et al. Effect of Noninvasive Ventilation vs Oxygen Therapy on Mortality Among Immunocompromised Patients With Acute Respiratory Failure: a Randomized Clinical Trial. JAMA 2015;314:1711-9.

6. Azoulay E, Pickkers P, Soares M, et al. Acute hypoxemic respiratory failure in immunocompromised patients: the
Efraim multinational prospective cohort study. Intensive Care Med 2017;43:1808-19.

7. Coudroy R, Pham T, Boissier F, et al. Is immunosuppression status a risk factor for noninvasive ventilation failure in patients with acute hypoxemic respiratory failure? A post hoc matched analysis. Ann Intensive Care 2019;9:90.

8. Thille AW, Contou D, Fragnoli C, et al. Non-invasive ventilation for acute hypoxemic respiratory failure: intubation rate and risk factors. Crit Care 2013;17:R269.

9. Carteaux G, Millán-Guilarte T, De Prost N, et al. Failure of Noninvasive Ventilation for De Novo Acute Hypoxemic Respiratory Failure: Role of Tidal Volume. Crit Care Med 2016;44:282-90.

10. Bellani G, Grasselli G, Teggia-Droghi M, et al. Do spontaneous and mechanical breathing have similar effects on average transpulmonary and alveolar pressure? A clinical crossover study. Crit Care 2016;20:142.

11. Duan J, Han X, Bai L, et al. Assessment of heart rate, acidosis, consciousness, oxygenation, and respiratory rate to predict noninvasive ventilation failure in hypoxemic patients. Intensive Care Med 2017;43:192-9.

12. Mokart D, Lambert J, Schnell D, et al. Delayed intensive care unit admission is associated with increased mortality in patients with cancer with acute respiratory failure. Leuk Lymphoma 2013;54:1724-9.

13. Wermke M, Schiemanck S, Höffken G, et al. Respiratory failure in patients undergoing allogeneic hematopoietic SCT — a randomized trial on early non-invasive ventilation 
based on standard care hematology wards. Bone Marrow Transplant 2012;47:574.

14. Antonelli M, Conti G, Bufi M, et al. Noninvasive ventilation for treatment of acute respiratory failure in patients undergoing solid organ transplantation: a randomized trial. JAMA 2000;283:235-41.

15. Squadrone V, Massaia M, Bruno B, et al. Early CPAP prevents evolution of acute lung injury in patients with hematologic malignancy. Intensive Care Med 2010;36:1666-74.

16. Lemiale V, Mokart D, Mayaux J, et al. The effects of a 2-h trial of high-flow oxygen by nasal cannula versus Venturi mask in immunocompromised patients with hypoxemic acute respiratory failure: a multicenter randomized trial. Crit Care 2015;19:380.

17. Azoulay E, Lemiale V, Mokart D, et al. Effect of HighFlow Nasal Oxygen vs Standard Oxygen on 28-Day Mortality in Immunocompromised Patients With Acute Respiratory Failure: The HIGH Randomized Clinical Trial. JAMA 2018;320:2099-107.

18. Frat JP, Ragot S, Girault C, et al. Effect of non-invasive oxygenation strategies in immunocompromised patients with severe acute respiratory failure: a post-hoc analysis of a randomised trial. Lancet Respir Med 2016;4:646-52.

19. Cortegiani A, Madotto F, Gregoretti C, et al. Immunocompromised patients with acute respiratory distress syndrome: secondary analysis of the LUNG SAFE database. Crit Care 2018;22:157.

20. Contejean A, Lemiale V, Resche-Rigon M, et al. Increased mortality in hematological malignancy patients with acute respiratory failure from undetermined etiology: a Groupe de Recherche en Réanimation Respiratoire en OncoHématologique (Grrr-OH) study. Ann Intensive Care 2016;6:102.

21. Azoulay E, Mokart D, Lambert J, et al. Diagnostic strategy for hematology and oncology patients with acute respiratory failure: randomized controlled trial. Am J Respir Crit Care Med 2010;182:1038-46.

22. Pallmann P, Bedding AW, Choodari-Oskooei B, et al. Adaptive designs in clinical trials: why use them, and how to run and report them. BMC Med 2018. doi:10.1186/ s12916-018-1017-7.

23. Lovejoy CA, Buch V, Maruthappu M. Artificial intelligence in the intensive care unit. Crit Care 2019. doi:10.1186/ s13054-018-2301-9

Cite this article as: Dumas G, Lemiale V, Demoule A, Azoulay E. Improving survival in immunocompromised patients with hypoxemic acute respiratory failure. Ann Transl Med 2019;7(Suppl 8):S293. doi: 10.21037/atm.2019.11.45 